\title{
Makna dan Ideologi Komunitas Sepeda Kebo di Surabaya dalam Kajian Subkultur
}

\section{Pariyanto}

Magister Kajian Sastra dan Budaya, Fakultas Ilmu Budaya Universitas

\author{
Airlangga, Surabaya, \\ Indonesia. \\ yantoboxs@gmail.com
}

\begin{abstract}
The rising popularity of modern bikes has replaced sepeda kebo (Indonesia's old-fashioned bike) as one of common means of transportation in Indonesia. Sepeda kebo nowadays is considered as antique that implicates on impression of sepeda kebo riding as nonmainstream activities. The riders belong to sepeda kebo cliques that introduce community-scaled companionship of riders. By implementing phenomenological paradigm, this qualitative research is motivated by three research questions: first, to investigate the significance of sepeda kebo clique for the members; second, to explore the importance of sepeda kebo clique membership for the members; and third, to illuminate the characterizing orientations initiated and evolved within sepeda kebo cliques in order to either promote the cliques as subculture or defining them as communal unit of interest. The research strategy consists of purposive sampling technique, participatory observation and in-depth interview as data collection method and Creswell's procedure as data analysis sequence.Sepeda kebo cliques in Surabaya are subcultures in globalization era and are forms of hybrid identity in coping with and resisting to mainstream cultures.

Keywords: old-fashioned bike, significance, orientation, clique, subculture
\end{abstract}

\section{Pendahuluan}

Arus globalisasi yang ditandai dengan semakin dinamisnya perkembangan kebudayaan akibat adanya gelombang pertukaran budaya antar-bangsa, akhirnya semakin memicu munculnya subkultur-subkultur baru (Soedarsono, 2002). Fenomena ini ditengarai timbul akibat: pertama, kesadaran masyarakat untuk mempertahankan kedudukan atau eksistensi kebudayaan lokal dari acaman kebudayaan asing. Kedua, maraknya subkultur di era globalisasi juga dipicu akibat terjadinya sentuhan kebudayan asing dengan kebudayan lokal atau mengalami proses akulturasi yang kemudian melahirkan sebuah subkultur.

Secara konseptual, subkultur merupakan sebuah gerakan atau kegiatan atau kelakuan (kolektif) atau bagian dari kultur yang besar. Biasanya digunakan sebagai bentuk perlawanan akan kultur mainstream tersebut. Berupa perlawanan terhadap agama, negara, institusi, musik, gaya hidup, dan segala yang dianggap mainstream (Barker, 2003: 374- 
409). Sedangkan budaya mainstream di era globalisasi sangat dimungkinkan juga merupakan budaya asing, yang akhirnya menjadi dominan. Berakar dari ini dapat diasumsikan bahwa subkultur di era globalisasi juga berupa bentuk perlawanan terhadap budaya mainstream yang berasal dari budaya asing.

Fenomena budaya ini pada akhirnya juga terjadi di Indonesia, sebagai negara kultur pluralis sangat memungkinkan untuk menjadi tempat tumbuhnya subkultur, contohnya fenomena komunitas kejawen, komunitas samin, komunitas vegetarian, komunitas musik punk, musik underground, tentunya termasuk komunitas sepeda kebo. Komunitas sepeda kebo ditengarai merupakan sebuah wujud subkultur yang lahir di era globalisasi. Dikatakan sebagai subkultur era globalisasi, komunitas sepeda kebo pada dasarnya berada dalam pengaruh arus budaya globalisasi yaitu kembali pada budaya ramah lingkungan dan sehat, melakukan aktivitas dengan alat transportasi yang tidak menyebabkan polusi udara, sehat bagi tubuh penggunanya, dan sebagai solusi pengurangan angka kemancetan di kotakota dengan menggunakan sepeda manual. Komunitas sepeda kebo meskipun turut menerapkan gaya hidup ramah lingkungan tetapi memberikan tawaran lain dengan memakai sepeda manual klasik atau sepeda kebo, beserta properti yang lain dalam komunitas sepeda kebo seperti pakaian tradisional Jawa, lurik Surabaya, beskap, serta ada juga yang menggunakan pakaian pejuang yang mencerminkan suasana perjuangan atau patriotisme yang menjadi identitas dari komunitas sepeda kebo.

Berawal dari fenomena ini peneliti berpendapat bahwa penelitian terkait komunitas sepeda kebo perlu dan menarik untuk dilakukan. Dikatakan menarik sebab di era globalisasi atau modern yang penuh dengan tawaran gaya hidup modern, komunitas sepeda kebo justru memilih gaya hidup klasik dengan menggunakan alat transportasi klasik (Sepeda Kebo). Komunitas sepeda kebo merupakan wujud komunitas di era globalisasi yang cukup berkembang. Terbukti komunitas sepeda kebo tercatat hampir ada di seluruh wilayah Indonesia khususnya di Pulau Jawa. 
Tercatat awal kelahiran komunitas sepeda kebo di Indonesia terjadi pada sekitar tahun 1990-an. Sampai sejauh ini belum diketahui secara jelas di daerah mana komunitas sepeda kebo bertama kali lahir di Indonesia. Namun beberapa sumber menyebutkan awal kebangkitan budaya bersepeda dengan sepeda kebo terjadi di Yogjakarta ${ }^{1}$. Sesuai data yang tercatat di KOSTI (Komunitas Sepeda Tua Indonesia) perkembangan komunitas sepeda kebo di seluruh Indonesia-dari Sabang sampai Meraoke, kurang lebih terdiri dari 210 komunitas $^{2}$.

Sesuai data KOSTI khusus di pulau Jawa: di Jawa Barat terdapat 48 komunitas, Jawa Tengah terdiri 20 komunitas, sedangkan di Jawa Timur terdapat 83 komunitas yang tersebar diseluruh kabupaten. Tercatat di Surabaya saja terdiri kurang lebih 35 komunitas tapi sampai saat ini yang terbilang cukup eksis kurang lebih ada 8 komunitas, diantaranya: COP (Comunitas Onthel Pasewangan) yang memiliki kurang lebih 30 anggota, KOSIM (Komunitas Onthel Simo) memiliki kurang lebih 25 anggota, PASKAS (Paguyupan Sepeda Kuno Arek Suroboyo) terdiri kurang lebih 50 anggota, SENOPATI (Sepeda Kuno Patriot Sejati) memiliki kurang lebih 50 anggota, KSOBRIS (Komunitas Sepada Ontel Bambu Runcing Surabaya) memiliki kurang lebih 35 anggota, D’PESOK (Perkumpulan Sepeda Onthel Kuno) terdiri kurang lebih 30 anggota, SMOC (Suramadu onthel Community) memiliki kurang lebih 20 anggota, dan GASELA (Gabungan Sepeda Lama) terdiri kurang lebih 25 anggota $^{3}$.

Keberadaan komunitas sepeda kebo khususnya di Surabaya kiranya dapat diasumsikan sebagai bentuk subkultur sebab merupakan sebuah gerakan, kegiatan, kelakuan (kolektif) atau bagian dari kultur yang besar. Komunitas sepeda kebo tentunya memiliki makna-makna terkait komunitas sepeda kebo yang ada di dalam komunitasnya, serta memiliki pandangan hidup atau ideologi yang berbeda dari budaya mainstream yang tentunya juga dibangun dan diaplikasikan dalam kehidupan para anggota komunitasnya. Melihat selama ini dari beberapa penelitian sebelumnya

\footnotetext{
${ }^{1}$ Lina, S.A. 2009. Romantisme Sepeda onthel, (online), (www.indosiar.com/ragam/romantisme-sepedaonthel.html, diakses 25 Juli 2014: 14.30).

2 www.kosti.or.id/pengprov/pengurus kosti propinsi, diakses 27 Mei 2014: 13.00

3 http://onthelclassic.wordpress.com/komunitas/ \& www.kosti.or.id, diakses 27 Mei 2014.
} 
belum ditemukan adanya upaya pembuktian apakah komunitas sepeda manual khususnya sepeda kebo yang begitu marak di Indonesia, khususnya di Jawa Timur merupakan sebuah cerminan subkultur di era globalisasi.

Kajian komunitas sepeda manual khususnya sepeda kebo masih tertentu dari aspek motivasi yaitu baik di balik pendirian sebuah komunitas dan motivasi masyarakat tertarik untuk menjadi anggota komunitas tersebut, serta terkait makna simbol-simbol yang dibangun dalam komunitas. Berdasar fakta ini maka peneliti akan melakukan penelitian terkait komunitas sepeda kebo dalam kajian subkultur prihal makna dan ideologi, guna membuktikan apakah fenomena komunitas sepeda kebo di Surabaya merupakan wujud subkultur.

Sejalan dengan pendahuluan yang dikemukaan di atas untuk menjaga fokus penelitian ini maka dirumuskan beberapa masalah pembahasan, sebagai berikut: bagaimana makna komunitas sepeda kebo di Surabaya bagi anggotanya ?; bagaimana makna menjadi anggota komunitas sepeda kebo di Surabaya menurut anggotanya ?; dan bagaimana ideologi yang dibentuk dan dibangun dalam komunitas sepeda kebo di Surabaya?

\section{Landasan Teori}

\section{Subkultur}

Subkultur dari awalan "sub" mengandung konotasi suatu kondisi yang khas dan berbeda dibandingkan dengan masyarakat dominan atau mainstream. Istilah subkultur autentik tergantung pada lawannya yaitu istilah budaya dominan atau budaya mainstream yang diproduksi massal dan tidak autentik (Barker, 2011: 341). Hartley (1976) mendefinisikan subkultur sebagai bentuk kolompok individu yang berbagi kepentingan, ideologi, dan praktik tertentu. Berakar dari definisi ini maka komunitas sepeda kebo dapat ditengarai sebagai bentuk perlawanan sekelompok masyarakat terhadap budaya mainstream khususnya mengenai alat transportasi di era globalisasi, semisal mobil, sepedah motor, dan pakaian. 
Serta memiliki kesamaan kepentingan, ideologi, dan praktik tertentu yang ingin disajikan lewat komunitas sepeda kebo.

Subkultur di era postmodernisme merupakan bentuk gaya hidup dalam pembentukkan identitas hibrida yaitu tidak adanya identitas asli, dimana globalisasi mampu menghapus batas regional, globalisasi menyediakan tempat untuk mengkontruksi identitas masyarakat di sisi lain menjadi non mainstream tapi disisi lain bisa mengikuti budaya mainstream (Thornton, 1995). Hibdige (1999) menyebutkan gaya hidup dalam subkultur dilakukan untuk resistensi terhadap budaya mainstream (budaya dominan).

\section{Makna dan Tanda}

Dalam studi subkultur seringkali memasukan studi tentang simbolisme (pakaian, musik, dan perilaku anggota sub kebudayaan) dan bagaimana simbol tersebut diinterpretasikan oleh kebudayaan induknya dalam pembelajarannya (Thornton, 1995). Berkaitan dengan definisi ini tentunya komunitas sepeda kebo juga memiliki makna-makna yang dicerminkan dalam simbol yang dibangun oleh anggota komunitasnya. Dalam teori semiotika Peirce, tanda (representamen) disebutkan sebagai bagian yang tidak terpisahkan dari objek referensinya serta pemahaman subjek terhadap tanda (interpretant). Tanda menurut Peirce adalah "....something which stands to somebody for something in some respect or capacity", dari definisi ini tampak peran subjek (somebody) sebagai bagian yang tidak terpisahkan dari pertandaan (Piliang, 2003). Peirce menilai subjek merupakan bagian yang tidak dapat dipisahkan dari proses signifikasi. Model triadik Peirce yang terdiri dari: (representamen + objek + interpretan $=$ tanda), memperlihatkan subjek memiliki peran besar dalam proses transformasi bahasa. Tanda menurut sudut padang Peirce selalu berada dalam proses perubahan tampa henti, yang disebut proses semiotika tidak terbatas (unlimited semiosis), yaitu proses penciptaan rangkaian interpretan yang tanpa akhir (Piliang, 2003).

Semiotika model triadik Peirce dijelaskan dalam trikotomi pertama: Qualisiqn, Sinsiqn, dan Legising; trikotomi kedua: Ikon, Indeks, 
dan Simbol; trikotomi ketiga: Rheme, Dicent, dan Dicent. Dimana setiap trikotomi terbagi tiga katagori diantaranya firstness yaitu makna kepertaman (fenomena), secondness adalah makna yang berkaitan dengan realitas (objek), dan thirdness merupakan hubungan antara kepertamaan (fenomena) dan kekeduaan (objek) dengan hukum dan aturan umum.

\section{Identitas dalam Subkultur}

Identitas adalah seluruh aspek sosial dan kultural, jadi identitas sepenuhnya merupakan kontruksi sosial dan tidak dapat eksis diluar representasi kultural dan akulturalisasi (Barker, 2011). Identitas dapat diekspresikan melalui bentuk representasi yang dapat dikenali oleh orang lain dan kita sendiri. Identitas dapat diasumsikan suatu esensi yang dapat dimaknai melalui tanda-tanda selera, kepercayaan, sikap, dan gaya hidup. Identitas atau subjek tidak bersifat otonom maupun berdiri sendiri, namun dibentuk dalam kaitannya orang lain yang berpengaruh, yang jadi perantara subjek dengan nilai, makna, dan simbol dalam masyarakat kita tinggal (Hall, 1992). Tanda-tanda selera, kepercayaan, sikap, dan gaya hidup merupakan cermin identitas, yang hanya dapat dipahami lewat bahasa. Identitas dalam komunitas sepeda kebo tentunya merupakan proses narasi tentang subjek, yang dicerminkan dalam nilai-nilai, simbol, gaya hidup, dan kepercayaan yang dibangun oleh anggota-anggota komunitas sepeda kebo.

\section{Ideologi dalam Subkultur}

Ideologi dalam Kamus Bahasa Indonesia (2008) diartikan sebagai sekumpulan konsep bersistem, cara berpikir seseorang atau suatu golongan manusia berupa paham, teori, dan tujuan berpadu yang merupakan satu program sosial politik. Menurut Hebdige (1999) karena ideologi memadati diskursus sehari-hari dalam bentuk akal sehat, ia tidak dapat dikelompokkan terpisah dari kehidupan sehari-hari sebagai serangkaian pendapat politis atau pandangan bias tertutup. Ideologi tidak dapat pula direduksi sebagai dimensi abstrak dari suatu pandangan hidup. Volosinov dalam Hebdige (1999) berpendapat setiap tanda dikenai kriteria evaluasi ideologis. Ranah ideologis bertemu dengan ranah tanda-tanda. Keduanya 
saling menyesuaikan. Kapan pun satu tanda hadir, ideologi hadir pula di situ. Segala sesuatu yang ideologis memiliki nilai semiotik. Sesuai dengan ini maka tanda-tanda yang dibangun dalam komunitas sepeda kebo juga memiliki makna, yang pastinya merupakan cerminan dari ideologi yang tubuh dan dibangun dalam komunitas sepeda kebo.

Althusser (dalam Barker, 2011) menyebutkan ideologi merupakan sistem yang merupakan representasi citra, mitos, gagasan, dan konsep, dipahami sebagai praktik yang dijalani dan mentransformasikan dunia materi. Produksi utama ideologi adalah subjek manusia (human subject). Melalui institusi-institusi dan ritual-ritual, ideologi mampu mentrasformasikan individu menjadi makhluk sosial (Althusser dalam Cavallaro 2001). Berkaitan dengan ini tentunya ideologi yang dibangun dalam komunitas sepeda kebo juga akan mampu memproduksi makhluk sosial khususnya anggotanya. Produksi ini berkaitan dengan pembentukan pandangan hidup atau paradigma, dimana akhirnya akan berpengaruh terhadap gaya hidup setiap anggota komunitas sepeda kebo.

\section{Metode Penelitian}

Penelitian ini merupakan penelitian kualitatif dengan desain penelitian fenomenologi. Paradigma penelitian fenomenologi memandang perilaku manusia sebagai produk dari cara orang tersebut menafsirkan dunianya (Furcah, 1992: 35). Pada dasarnya penelitian fenomenologi berpandangan bahwa apa yang tampak di permukaan, termasuk pola perilaku manusia sehari-hari hanya suatu gejala atau fenomena dari apa yang tersebunyi di kepala sang pelaku. Lokasi penelitian dilakukan di Kota Surabaya, lebih khususnya, penelitian dilakukan di Taman Bungkul setiap hari minggu pada acara Car Free Day, serta jika ada acara di tempat lain semisal saat ada kirap sepeda kebo. Penelitian dilakukan mulai awal Februari sampai akhir Juli 2014.

Pengambilan sampel menggunakan teknik sampel bertujuan (purpossive sampling) adalah teknik penentuan sampel dengan pertimbangan tertentu (Patton, 1990). Pengambilan data dilakukan dengan 
metode observasi partisipasi dan wawancara mendalam (in-depth interview). Observasi partisipasi (Bungin, 2008) diartikan sebagai jenis pengamatan yang melibatkan peneliti dalam kegiatan orang yang menjadi sasaran peneliti, tanpa mengakibatkan perubahan pada kegiatan yang bersangkutan, dan tidak menyembunyikan diri. Teknik wawancara mendalam (in-depth interview), menurut Bungin (2008) merupakan metode wawancara yang lebih menekankan pada kedalaman informasi, wawancara mendalam dilakukan secara berulang kali guna menggali pandangan subjek yang diteliti tentang fokus penelitian, yang sangat bermanfaat untuk menjadi dasar bagi penggalian informasinya secara lebih jauh dan mendalam.

Analisis data menggunakan metode yang ditawarkan Creswell, dalam bukunya yang berjudul Qualitaive Inquiry and Research Design: Choosing Among Five Traditions (dalam Kuswarno, 2009: 71-72), Creswell mengemukakan teknik analisis data sebagai berikut:

\begin{tabular}{|c|c|}
\hline $\begin{array}{c}\text { Analisis dan } \\
\text { Representasi Data }\end{array}$ & Langkah Penelitian Fenomenologi \\
\hline Pengolahan data & Membuat dan mengorganisasikan data \\
\hline $\begin{array}{l}\text { Membaca dan } \\
\text { mengingat data }\end{array}$ & $\begin{array}{l}\text { Membaca teks, membuat batasan-batasan } \\
\text { catatan, dan membuat form kode-kode inisial }\end{array}$ \\
\hline Mengklasifikasi data & $\begin{array}{l}\text { - Menemukan pernyataan-pernyataan } \\
\text { bermakna, dan membuat daftarnya } \\
\text { - } \begin{array}{l}\text { Mengelompokkan pernyataan-pernyataan } \\
\text { yang sama ke dalam unit-unit tertentu }\end{array} \\
\end{array}$ \\
\hline Interprestasi data & 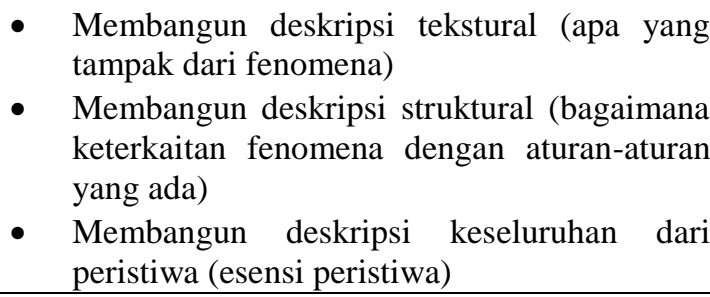 \\
\hline $\begin{array}{ll}\text { Visualisasi dan } & \\
\text { presentasi data } & \end{array}$ & $\begin{array}{l}\text { Narasi esensi peristiwa, dilengkapi dengan } \\
\text { tabel pernyataan, dan unit-unit makna }\end{array}$ \\
\hline
\end{tabular}

Tabel 1. Teknik Analisi Data Model Creswell

\section{Hasil dan Pembahasan}

\section{Makna Komunitas Sepeda Kebo di Surabaya Bagi Anggotanya}

Bahasa mampu menciptakan tanda-tanda yang digunakan oleh manusia untuk menciptakan makna-makna guna mengambarkan 
realitasnya (Barry 2002). Tanda-tanda yang ada dalam komunitas sepeda kebo di Surabaya adalah gambaran realitas sosial yang dibangun dan dibentuk dalam komunitas sepeda kebo di Surabaya. Terutama pada sub bab ini, terkait tanda-tanda yang dibentuk untuk mengambarkan makna komunitas sepeda kebo.

Berdasarkan teori semiotika Peirce bahwa tanda dibentuk oleh tiga elemen, diantaranya: pertama, representamen adalah sesuatu yang merepresentasikan sesuatu yang lain, yang paling lekat dengan objek yang diwakilinya, kedua, objek yaitu sesuatu yang direpresentasikan, dan ketiga, interpretan adalah interpretasi seseorang tentang atau terhadap tanda (Piliang, 2003). Secara garis besar berdasarkan hasil observasi partisipasi dan wawancara mendalam (in-depth interview) pada beberapa komunitas sepeda kebo di Surabaya, ditemukan bahwa komunitas sepeda kebo merupakan tanda yang dibangun untuk mengambarkan realitas komunitas sepeda kebo, sebagai bentuk persaudaraan, kekeluargaan, kerukunan, melestarikan budaya, dan guyup. Lihat grafik 1 sebagai berikut:

\section{Representamen}

(GASELA, KOSIM, PASKAS, COP, SMOC,

D'PESOK, SENOPATI, KSOBRIS, KOSTI Surabaya)

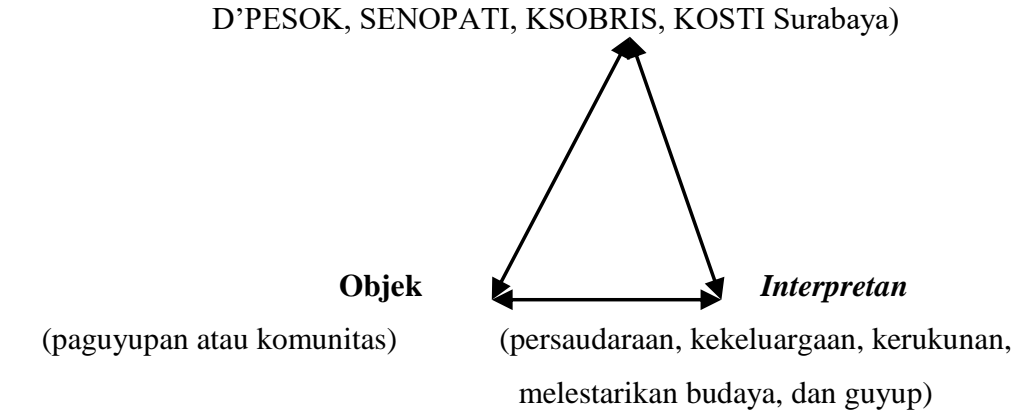

Grafik 1. Semiotika Model Triadik Peirce: makna komunitas sepeda kebo di Surabaya

Definisi ini dapat ditemukan pada hasil wawancara mendalam dengan beberapa anggota komunitas sepeda kebo di Surabaya, lihat tabel 2 berikut ini:

\begin{tabular}{|c|l|l|}
\hline $\begin{array}{c}\text { Nama } \\
\text { komunitas }\end{array}$ & Informan & Makna Komunitas Sepeda Kebo \\
\hline SENOPATI & Pak & - Kerukunana, persaudaraan \\
& Soetopo & - Kerukunana, persaudaraan, guyup \\
& Mas Ivan & - Kerukunana, persaudaraan, guyup \\
\hline
\end{tabular}




\begin{tabular}{|c|c|c|}
\hline & Mas Rio & \\
\hline GASELA & $\begin{array}{l}\text { Mas Por } \\
\text { Cak Nan }\end{array}$ & $\begin{array}{l}\text { - persaudaraan, guyup } \\
\text { - persaudaraan, guyup }\end{array}$ \\
\hline KOSIM & $\begin{array}{l}\text { Pak Samsul } \\
\text { Mas } \\
\text { Sugihartono } \\
\text { Mas Bagus }\end{array}$ & $\begin{array}{l}\text { - persaudaraan, guyup } \\
\text { - persaudaraan } \\
\text { - persaudaraan, guyup }\end{array}$ \\
\hline D'PESOK & $\begin{array}{l}\text { Pak Nanang } \\
\text { Pak Bahri } \\
\text { Pak } \\
\text { Rohimin }\end{array}$ & $\begin{array}{l}\text {-persaudaraan } \\
\text {-persaudaraan, guyup } \\
\text {-persaudaraan, guyup }\end{array}$ \\
\hline KSOBRIS & $\begin{array}{l}\text { Pak } \\
\text { Suyetno } \\
\text { Mbah Sadji }\end{array}$ & $\begin{array}{l}\text { - melestarikan budaya (uri-uri budaya), } \\
\text { kerukunan, persaudaraan, guyup } \\
\text { - melestarikan budaya (uri-uri budaya), } \\
\text { kerukunan, persaudaraan, guyup }\end{array}$ \\
\hline COP & $\begin{array}{l}\text { Pak Piyadi } \\
\text { Pak Jumadi } \\
\text { Pak Budi }\end{array}$ & $\begin{array}{l}\text { - persaudaraan, kekeluargaan, guyup } \\
\text { - persaudaraan, kekeluargaan } \\
\text { - persaudaraan, kekeluargaan }\end{array}$ \\
\hline SMOC & $\begin{array}{l}\text { Pak Dedik } \\
\text { Mas ikbal }\end{array}$ & $\begin{array}{l}\text { - persaudaraan, kekeluargaan } \\
\text { - Persaudaraan, kekeluargaan }\end{array}$ \\
\hline PASKAS & $\begin{array}{l}\text { Pak Eko } \\
\text { Pak } \\
\text { Santoso } \\
\text { MY } \\
\end{array}$ & $\begin{array}{l}\text {-melestraikan budaya, persaudaraan, } \\
\text { rukun, guyup } \\
\text {-persaudaraan, rukun, guyup } \\
\text { - persaudaraan, rukun, guyup }\end{array}$ \\
\hline $\begin{array}{l}\text { Onthelis } \\
\text { Keliling } \\
\text { Nusantara }\end{array}$ & Pak Suyono & -persaudaraan \\
\hline $\begin{array}{l}\text { KOSTI } \\
\text { Surabaya }\end{array}$ & Pak Slamet & -persaudaraan \\
\hline
\end{tabular}

Tabel 2: hasil wawancara mendalam makna komunitas sepeda kebo

di Surabaya menurut anggotanya

Tanda SENOPATI, PASKAS, KOSIM, SMOC, COP, D'PESOK, KSOBRIS, GASELA, dan KOSTI Surabaya adalah tanda yang di pahami pada tahap awal (Firstness) berfungsi sebagai representamen yaitu ikon yang paling lekat dengan objek yang diwakili yaitu para pencinta dan pengguna sepeda kebo serta budaya tempo dulu, seperti pakaian tradisonal: lurek, beskap, tradisi Jawa, tradisi Madura dan pakaian perjuangan (cerita sejarah): BKR, TKR, pakaian bung karnoan, pakaian tentara Jepang, Belanda, dan Inggris. Sehingga tanda dikenal pada tahap awal sebagai bentuk perkumpulan atau kelompok pengguna dan pecinta sepeda kebo serta budaya tempo dulu (Sinsiqn) sebab SENOPATI merupakan singkatan Sepeda Koeno Patriot Sedjati, GASELA adalah singkatan Gabungan Sepeda Lawas, KOSIM merupakan singkatan 
Komunitas Onthel Simo, D'PESOK adalah singkatan Perkumpulan Sepeda Onthel Kuna, KSOBRIS merupakan singkatan Komunitas Sepeda Onthel Bambu Runcing Surabaya, COP adalah singkatan Comunitas Onthel Pasewanga, SMOC merupakan singkatan Suramadu Onthel Club, PASKAS adalah singkatan Paguyupan Sepeda Tua Arek Surabaya, dan KOSTI Surabaya merupakan singkatan Komunitas Sepeda Kuna Indonesia Korwil Surabaya (Legising).

Secondness penggunaan tanda SENOPATI, PASKAS, KOSIM, SMOC, COP, D'PESOK, KSOBRIS, GASELA, dan KOSTI Surabaya sebagai bentuk perkumpulan atau kelompok pengguna dan pecinta sepeda kebo serta budaya tempo dulu (ikon) sebab merupakan wadah para pengguna dan pecinta sepeda kebo dan budaya tempo dulu (indeks). Indeks menjadi pengingat bahwa masih ada tanda yang utama meskipun ditandai secara individu oleh onthelis bahwa SENOPATI, PASKAS, KOSIM, SMOC, COP, D'PESOK, KSOBRIS, GASELA, dan KOSTI Surabaya merupakan tanda paguyupan atau komunitas sepeda kebo (simbol).

Sementara Thirdness komunitas sepeda kebo sebagai tempat perkumpulan dan silaturahmi para pengguna dan pencinta sepeda kebo dan tempo dulu (Rheme) yang memiliki makna (interpretan) sebagai bentuk persaudaraan, kekeluargaan, kerukunan, melestarikan budaya, dan guyup sesama onthelis (Dicent). Makna ini sesuai dengan pengertian paguyupan merupakan tempat atau wadah masyarakat yang memiliki ide dan kesukaan sama (sepaham) untuk membina persatuan dan kerukunan diantara anggota, visi dan misi komunitas sepeda kebo untuk menjalin persaudaraan, kekeluangan, kerukunan, dan guyup sesama ontheli, serta melestarikan sepeda kebo dan budaya tempo dulu, seperti pakain tradisional dan pakaian perjuangan (Argument).

Hasil penelitian ini membuktikan keberadaan komunitas sepeda kebo menjadi media untuk menumbuhkan dan mempertahankan nilai-nilai ke-Indonesia-an dengan tujuan agar masyarakat Indonesia khususnya generasi muda tau dan memiliki gaya hidup sesuai dengan nilai-nilai 
budaya Indonesia yaitu gaya hidup menjalin persaudaraan, kekeluargaan, kerukunan, melestarikan budaya, dan guyup guna mewujudkan butir Pancasila ke-3 Persatuan Indonesia. Komunitas sepeda kebo di Surabaya merupakan resistensi budaya asing yang keberadaannya telah mengantikan budaya lokal sebab onthelis menjadikan komunitas sepeda kebo sebagai bentuk budaya tandingan (counter culture) budaya lokal terhadap tantangan budaya yang dibawa arus globalisasi seperti individualis.

\section{Makna Menjadi Anggota Komunitas Sepeda Kebo di Surabaya Menurut Anggotanya}

Realitas sosial dalam komunitas sepeda kebo di Surabaya dibentuk melalui tanda-tanda selera, nilai-nilai, kepercayaan, sikap, dan gaya hidup yang ada dan dibangun didalamnya. Tanda-tanda dalam komunitas sepeda kebo merupakan gambaran identitas yang dinarasikan oleh anggota komunitas sepeda kebo di Surabaya. Dalam bagian ini akan dijelaskan terkait tanda-tanda yang dibentuk untuk mengambarkan makna menjadi anggota komunitas sepeda kebo.

Berkaitan dengan teori semiotika Peirce bahwa tanda dibentuk oleh tiga elemen, diantaranya: (1) representamen adalah sesuatu yang merepresentasikan sesuatu yang lain yang paling lekat dengan objek yang diwakilinya, (2) objek yaitu sesuatu yang direpresentasikan oleh anggota komunitas sepeda kebo, dan (3) interpretan adalah interpretasi seseorang tentang atau terhadap tanda (Piliang, 2003). Secara garis besar berdasarkan hasil observasi partisipasi dan wawancara mendalam (in-depth interview), tanda-tanda yang dibentuk dan dibangun dalam komunitas sepeda kebo di Surabaya, mengambarkan makna menjadi anggota komunitas sepeda kebo sebagai identitas memiliki kesadaran untuk melestarikan budaya (uri-uri budaya), berjiwa sosial, kesederhanaan, berjiwa kepahlawan, dan sehat. Lihat grafik 3 sebagai berikut :

\section{Representamen}


pakaian khas Madura, dan pakaian perjuangan: BKR, TKR, pakaian

Bung Karnoan, pakaian tentara Jepang, Belanda, dan Inggris)

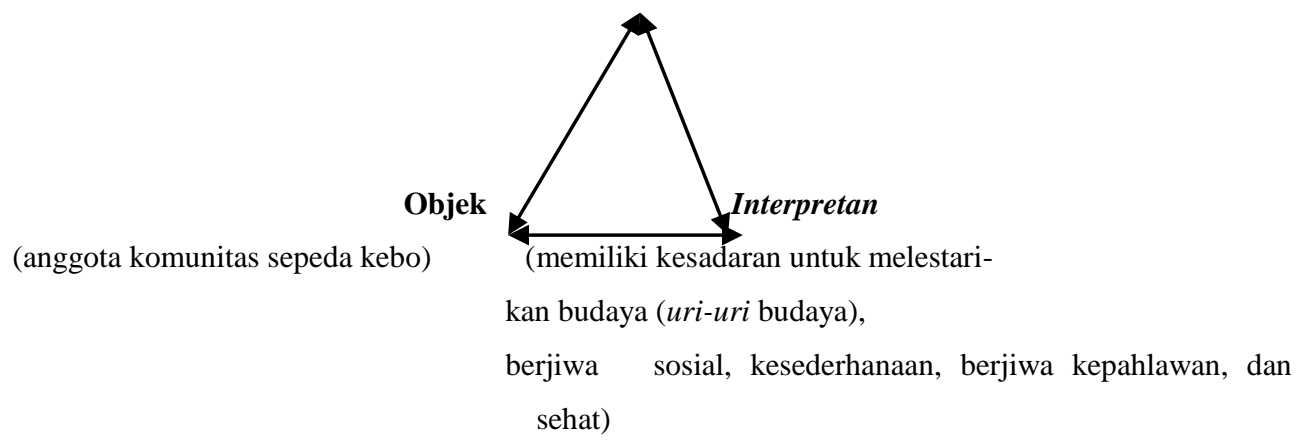

Grafik 3. Semiotika Model Triadik Peirce: makna menjadi anggota komunitas sepeda kebo di Surabaya

Definisi ini dapat ditemukan pada hasil wawancara mendalam dengan beberapa anggota komunitas sepeda kebo di Surabaya, lihat tabel 3 berikut ini:

\begin{tabular}{|c|c|c|}
\hline $\begin{array}{c}\text { Nama } \\
\text { komunitas }\end{array}$ & Informan & $\begin{array}{c}\text { Makna Menjadi Anggota Komunitas } \\
\text { Sepeda Kebo }\end{array}$ \\
\hline SENOPATI & $\begin{array}{l}\text { Pak } \\
\text { Soetopo } \\
\text { Mas Ivan } \\
\text { Mas Rio }\end{array}$ & $\begin{array}{l}\text {-sehat, memiliki kesadaran untuk } \\
\text { melestarikan budaya (uri-uri budaya), dan } \\
\text { kesederhanaan } \\
\text { - memiliki kesadaran untuk melestarikan } \\
\text { budaya (uri-uri budaya) } \\
\text { - memiliki kesadaran untuk melestarikan } \\
\text { budaya (uri-uri budaya) }\end{array}$ \\
\hline GASELA & $\begin{array}{l}\text { Mas Por } \\
\text { Cak Nan }\end{array}$ & $\begin{array}{l}\text { - memiliki kesadaran untuk melestarikan } \\
\text { budaya (uri-uri budaya), berjiwa sosial } \\
\text {-memiliki kesadaran untuk melestarikan } \\
\text { budaya (uri-uri budaya), berjiwa sosial }\end{array}$ \\
\hline KOSIM & $\begin{array}{l}\text { Pak Samsul } \\
\text { Mas } \\
\text { Sugihartono } \\
\text { Mas Bagus }\end{array}$ & $\begin{array}{l}\text { - memiliki kesadaran untuk melestarikan } \\
\text { budaya (uri-uri budaya), berjiwa sosial } \\
\text {-memiliki kesadaran untuk melestarikan } \\
\text { budaya (uri-uri budaya), berjiwa sosial } \\
\text {-memiliki kesadaran untuk melestarikan } \\
\text { budaya (uri-uri budaya), berjiwa sosial }\end{array}$ \\
\hline D'PESOK & $\begin{array}{l}\text { Pak Nanang } \\
\text { Pak Bahri } \\
\text { Pak } \\
\text { Rohimin }\end{array}$ & $\begin{array}{l}\text {-memiliki kesadaran untuk melestarikan } \\
\text { budaya (uri-uri budaya), berjiwa sosial, } \\
\text { berjiwa kepahlawanan } \\
\text {-memiliki kesadaran untuk melestarikan } \\
\text { budaya (uri-uri budaya), berjiwa sosial } \\
\text {-memiliki kesadaran untuk melestarikan } \\
\text { budaya (uri-uri budaya), berjiwa sosial }\end{array}$ \\
\hline KSOBRIS & $\begin{array}{l}\text { Pak } \\
\text { Suyetno } \\
\text { Mbah Sadji }\end{array}$ & $\begin{array}{l}\text {-memiliki kesadaran untuk melestarikan } \\
\text { budaya (uri-uri budaya), berjiwa sosial, } \\
\text { berjiwa kepahlawanan } \\
\text {-memiliki kesadaran untuk melestarikan } \\
\text { budaya (uri-uri budaya), berjiwa sosial, } \\
\text { berjiwa kepahlawanan }\end{array}$ \\
\hline
\end{tabular}




\begin{tabular}{|c|c|c|}
\hline COP & $\begin{array}{l}\text { Pak Piyadi } \\
\text { Pak Jumadi } \\
\text { Pak Budi }\end{array}$ & $\begin{array}{l}\text {-memiliki kesadaran untuk melestarikan } \\
\text { budaya (uri-uri budaya), berjiwa sosial, } \\
\text { kesederhanaan } \\
\text {-memiliki kesadaran untuk melestarikan } \\
\text { budaya (uri-uri budaya), berjiwa sosial }\end{array}$ \\
\hline SMOC & $\begin{array}{l}\text { Pak Dedik } \\
\text { Mas ikbal }\end{array}$ & $\begin{array}{l}\text {-memiliki kesadaran untuk melestarikan } \\
\text { budaya (uri-uri budaya), berjiwa sosial, } \\
\text { sehat } \\
\text {-memiliki kesadaran untuk melestarikan } \\
\text { budaya (uri-uri budaya), berjiwa sosial, } \\
\text { sehat }\end{array}$ \\
\hline PASKAS & $\begin{array}{l}\text { Pak Eko } \\
\text { Pak } \\
\text { Santoso } \\
\text { MY }\end{array}$ & $\begin{array}{l}\text {-memiliki kesadaran untuk melestarikan } \\
\text { budaya (uri-uri budaya), berjiwa sosial, } \\
\text { sehat } \\
\text {-memiliki kesadaran untuk melestarikan } \\
\text { budaya (uri-uri budaya), berjiwa sosial } \\
\text {-memiliki kesadaran untuk melestarikan } \\
\text { budaya (uri-uri budaya), berjiwa sosial }\end{array}$ \\
\hline $\begin{array}{l}\text { Onthelis } \\
\text { Keliling } \\
\text { Nusantara }\end{array}$ & Pak Suyono & $\begin{array}{l}\text {-memiliki kesadaran untuk melestarikan } \\
\text { budaya (uri-uri budaya), berjiwa sosial }\end{array}$ \\
\hline $\begin{array}{l}\text { KOSTI } \\
\text { Surabaya }\end{array}$ & Pak Slamet & $\begin{array}{l}\text {-memiliki kesadaran untuk melestarikan } \\
\text { budaya (uri-uri budaya), berjiwa sosial }\end{array}$ \\
\hline
\end{tabular}

Tabel 3: hasil wawancara mendalam makna menjadi anggota

komunitas sepeda kebo di Surabaya

Tanda sepeda kebo, pakaian tradisional seperti lurek, beskap, tradisi Jawa, tradisi Madura, dan pakaian perjuangan (cerita sejarah) seperti BKR, TKR, pakaian bung karnoan, pakaian tentara Jepang, Belanda, dan Inggris merupakan tanda yang dipahami pada tahap awal (Firstness) berlaku sebagai representamen yaitu ikon yang paling lekat dengan objek yang diwakili yaitu tanda keanggotaan komunitas sepeda kebo (Sinsiqn). Dimana onthelis merupakan masyarakat yang memiliki dan menggunakan sepeda kebo dan budaya tempo dulu seperti pakaian tradisional dan pakaian perjuangan (Legising).

Secondness tanda sepeda kebo, pakaian tradisional seperti lurek, beskap, tradisi Jawa, tradisi Madura, dan pakaian perjuangan (cerita sejarah) seperti BKR, TKR, pakaian bung karnoan, pakaian tentara Jepang, Belanda, dan Inggris merupakan bentuk keanggotaan onthelis dalam komunitas sepeda kebo (ikon) karena onthelis merupakan pengguna dan pecinta sepeda kebo dan budaya tempo dulu (indeks). Kehadiran indeks menjadi pengingat bahwa masih ada tanda utama, meskipun masih ditandai secara individu oleh onthelis bahwa sepeda kebo dan budaya 
tempo dulu seperti pakaian tradisional dan pakaian perjuangan adalah tanda anggota komunitas sepeda kebo (simbol).

Sedangkan Thirdness penggunaan tanda sepeda kebo, pakaian tradisional, dan pakaian perjuangan merupakan bentuk onthelis memiliki rasa cinta terhadap budaya tradisional, melestarikan budaya tempo dulu, dan memiliki rasa kebersamaan dan tolong menolong sesama onthelis (Rheme), yang mana menjadi anggota komunitas sepeda kebo memiliki makna (interpretan) sebagai identitas memiliki kesadaran untuk melestarikan budaya, berjiwa sosial, kesederhanaan, berjiwa kepahlawanan, dan sehat (Dicent) sebab onthelis memiliki semangat dan niat melestarikan sepeda kebo dan budaya tempo dulu ditengah mayoritas masyarakat sudah melupakannya, memiliki rasa kebersamaan, tolong menolong, dan saling menghargai sesama onthelis, sepeda kebo merupakan alat transportasi ramah lingkungan dan dapat digunakan olah raga, dan onthelis memiliki kebanggaan untuk menggunakan pakaian perjuangan (Argument).

Sepeda kebo, pakaian perjuangan, dan pakaian budaya tradisional adalah tanda untuk menarasikan bahwa onthelis adalah individu memiliki kesadaran untuk melestarikan budaya dan berjiwa kepahlawanan karena saat mayoritas masyarakat sudah melupakan budaya tempo dulu, onthelis masih memiliki motivasi dan kebangaan untuk memiliki dan menggunakannya. Individu berjiwa sosial diwakili oleh tanda sepeda kebo sebab pengguna sepeda kebo merupakan individu yang memiliki rasa kebersamaan dan tolong menolong sesama onthelis dan masyarakata di luar komunitas sepeda kebo. Sepeda kebo juga mengambarkan identitas sehat sebab sepeda kebo merupakan alat transportasi ramah lingkungan dan dapat digunakan olah raga.

Menjadi anggota komunitas sepeda kebo merupakan bentuk upaya mengembalikan nilai-nilai ke-Indonesia-an, falsafah bangsa Indonesia yang tercermin dalam butir Pancasila ke-3 yaitu Persatuan Indonesia. Mengembalikan gaya hidup untuk menjalin persaudaraan dan kerukunan sesama masyarakat Indonesia yang sudah hilang dari masyarakat 
Indonesia, dengan menekankan dan mencontohkan bahwa onthelis sebagai individu berjiwa sosial dan kesederhanaan kepada masyarakat Indonesia khususnya generasi muda. Serta guna mengingatkan kembali dan memberikan pelajaran kepada masyarakat Indonesia khususnya generasi muda terhadap budaya lokal dan cerita sejarah bangsa untuk menciptakan rasa Nasionalisme yang mulai berkurang di era globalisasi. Menjadi anggota komunitas sepeda kebo di Surabaya merupakan resistensi budaya asing yang keberadaannya telah mengantikan budaya lokal sebab onthelis menjadikan komunitas sepeda kebo sebagai wadah membangun pribadi ke-Indonesia-an sebagai bentuk budaya tandingan (counter culture) budaya lokal terhadap tantangan budaya yang dibawa arus globalisasi yang bersifat individualis, hidonis, dan kapitalis.

\section{Ideologi yang Dibentuk dan Dibangun Dalam Komunitas Sepeda} Kebo di Surabaya

Ranah ideologi bertemu dengan ranah tanda-tanda. Keduanya saling menyesuaikan, kapan pun satu tanda hadir, ideologi hadir pula di situ. Segala sesuatu yang ideologi memiliki nilai semiotik (Hebdige, 1999). Berkait dengan ini realitas dalam komunitas sepeda kebo di Surabaya, tanda-tanda yang tercermin dalam cara berpikir berupa paham, teori, dan tujuan berpadu yang dibangun di dalam komunitas sepeda kebo merupakan bentuk ideologi. Ideologi adalah sistem yang merupakan representasi citra, mitos, gagasan, dan konsep, dipahami sebagai praktik yang dijalani dan mentransformasikan dunia materi. Produksi utama ideologi adalah subjek manusia (human subject) (Althusser dalam Barker, 2011). Maka gagasan dan konsep yang digunakan untuk membangun identitas anggota komunitas sepeda kebo adalah wujud ideologi yang berkembang di dalam komunitas sepeda kebo di Surabaya.

Sesuai dengan hasil observasi partisipan dan wawancara mendalam dengan beberapa informan dari komunitas sepeda kebo di Surabaya. Tanda-tanda yang dibangun lewat cara berpikir seperti paham, teori, dan tujuan berpadu dalam komunitas sepeda kebo di Surabaya merupakan sebuah wujud ideologi persatuan dan kesatuan dan nasionalisme. Ideologi 
persatuan dan kesatuan dapat ditemukan pada paham, teori, dan tujuan berpadu yang dibentuk dan dibangun dalam komunitas sepeda kebo di Surabaya bahwa komunitas sepeda kebo merupakan paguyupan atau komunitas sebagai wadah untuk menjalin persaudaraan, kekeluargaan, kerukunan, dan guyup antar anggota komunitas, sesama komunitas sepeda kebo lain, dan masyarakat di luar komunitas sepeda kebo. Dimana ideologi persatuan dan kesatuan ini akhirnya mampu menbentuk individu (human subject) yang berjiwa sosial dan kesederhanaan sebagai bentuk identitas yang dikontruksi dan dinarasikan dalam komunitas sepeda kebo di Surabaya.

Ideologi nasionalisme ditemukan dari paham, teori, dan tujuan berpadu komunitas sepeda kebo di Surabaya bahwa komunitas sepeda kebo merupakan upaya untuk melestarikan budaya, terkait cerita sejarah dan budaya lokal seperti sepeda kebo, beskap, lurik Surabaya, pakaian tradisi Jawa, dan pakaian perjuangan. Dimana akhirnya ideologi nasionalisme dapat membentuk individu (human subject) yang memiliki kesadaran untuk melestarikan budaya dan berjiwa kepahlawanan sebuah bentuk identitas yang dikontruksi dan dinarasikan dalam komunitas sepeda kebo di Surabaya. Lihat gambar 1 berikut ini:
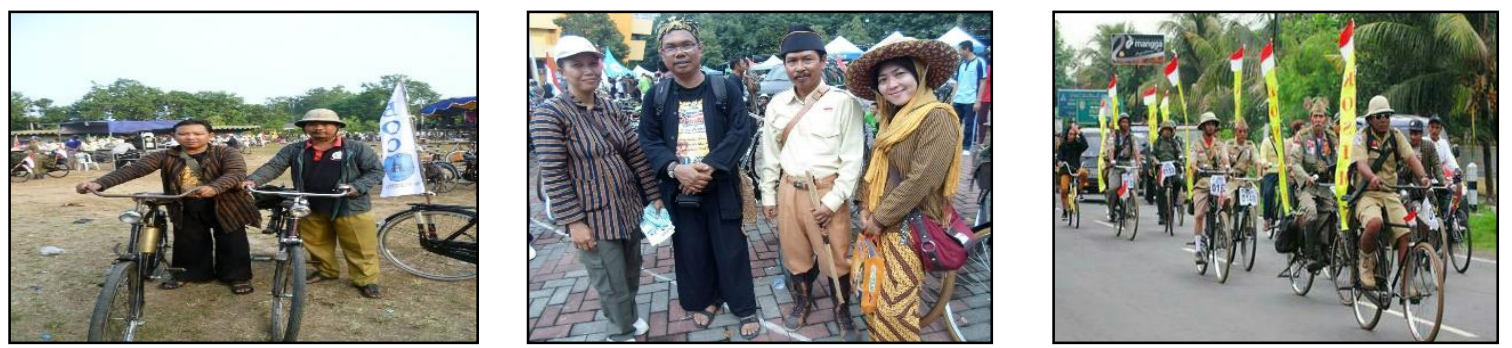

Gambar 1. Beberapa Anggota Komunitas Sepeda Kebo di Surabaya

Onthelis menjadikan komunitas sepeda kebo sebagai tempat pertahanan ideologi ke-Indonesia-an terkait falsafah bangsa Indonesia yaitu gaya hidup untuk menjalin persaudaraan dan kerukunan sesama masyarakat Indonesia sebagai mana tertulis pada butir Pancasila ke-3 yaitu Persatuan Indonesia, yang sudah mulai hilang dari masyarakat Indonesia. Mayoritas masyarakat Indonesia sudah menjadi pribadi individualis yang bukan merupakan nilai-nilai budaya Indonesia, namun adalah bentuk 
budaya yang dibawa era globalisasi. Onthelis menjadikan komunitas sepeda kebo di Surabaya sebagai bentuk resistensi terhadap ideologi yang dibawa budaya asing untuk mempertahankan ideologi ke-Indonesia-an yaitu ideologi persatuan dan kesatuan dan ideologi nasionalisme. Komunitas sepeda kebo di Surabaya merupakan budaya tandingan (counter culture) budaya lokal terhadap ideologi yang dibawa budaya di era globalisasi yaitu individualisme dan kapitalisme.

\section{Posisi Komunitas Sepeda Kebo di Surabaya dalam Subkultur}

Motivasi onthelis anggota komunitas sepeda kebo untuk melestarikan budaya ngonthel (bersepeda dengan sepeda kebo), sepeda kebo, dan budaya tempo dulu yang lain ditengah mayoritas masyarakat Indonesia yang sudah meninggalkan budaya tempo dulu dengan menggunakan produk budaya modern merupakan bentuk perlawanan, memberikan solusi, dan budaya tandingan (counter culture) terhadap budaya mainstream atau dominan. Anggota komunitas sepeda kebo menawarkan sepeda kebo yang merupakan alat transportasi ramah lingkungan serta bisa digunakan untuk olah raga dan pakaian budaya tempo dulu untuk melestarikan budaya Indonesia, sebagai solusi budaya diera modern. Temuan ini sesuai dengan definisi bahwa subkultur merupakan bagian kultur dominan yang bersifat melawan terhadap budaya mainstream atau dominan (Barker, 2011).

Perlawanan budaya mainstream pada komunitas sepeda kebo di Surabaya, namun tidak se-ekstrim komunitas musik punk dan musik underground, komunitas sepeda kebo hanya memberikan contoh dan motivasi kepada masyarakat Indonesia khususnya generasi muda untuk tidak melupakan budaya lokal, dengan jalan tetap mempertahankan eksistensi atau keberadaan sepeda kebo dan pakaian tempo dulu. Perlawanan terhadap budaya dominan dalam komunitas sepeda kebo terwujud dalam semangat dan motivasi anggota komunitas sepeda kebo untuk memiliki dan menggunakan sepeda kebo dan pakaian tempo dulu saat ada acara komunitas sepeda kebo, seperti kirap sepeda kebo pada peringatan hari pahlawan, ulang tahun hari jadi Surabaya, ulang tahun hari 
jadi komunitas sepeda kebo, dan di Car Free Days. Adapun beberapa onthelis yang memiliki gaya hidup menggunakan sepeda kebo dan pakaian tempo dulu secara total ditemukan pada onthelis Keliling Nusantara dan pada sebagian anggota komunitas sepeda kebo yang dalam kehidupan sehari-harinya menggunakan sepeda kebo dan pakaian tradisional seperti lurik khas Jawa dipadukan dengan blangkon.

Komunitas sepeda kebo secara mayoritas juga memiliki ideologi keindonesiaan yang berkembang di budaya mainstream yaitu ideologi persatuan dan kesatuan dan ideologi nasionalisme. Ideologi persatuan dan kesatuan yang disimbolkan dengan komunitas sepeda kebo yang ditujukan untuk menjalin kerukunan, persaudaraan, kekeluargaan, dan guyup sesama onthelis. Ideologi nasionalisme yang disimbolkan dengan penggunaan sepeda kebo, pakaian tradisional, dan pakaian perjuangan yang digunakan untuk menjaga kelestarian budaya tempo dulu.

Berdasarkan temuan ini komunitas sepeda kebo di Surabaya terbagi menjadi dua bagian, pertama, mayoritas anggota komunitas sepeda kebo memiliki gaya hidup non-mainstream hanya dalam acara komunitas sepeda kebo, sementara dalam kehidupan sehari-harinya mengikuti budaya mainstream. Kedua, minoritas onthelis anggota komunitas sepeda kebo di Surabaya, seperti onthelis pelaku Keliling Nusantara dan sebagian anggota komunitas sepeda kebo yang latar belakangnya seniman ataupun veteran memiliki gaya hidup non-mainstream secara total dalam kehidupannya yang diwujudkan dengan menggunakan sepeda kebo dan budaya tempo dulu dalam kehidupanya sehari-hari.

Fenomena budaya komunitas sepeda kebo di Surabaya sesuai dengan konsep subkultur era globalisasi merupakan bentuk gaya hidup dalam pembentukkan identitas hibrida yaitu tidak adanya identitas asli, dimana globalisasi mampu menghapus batas regional, globalisasi menyediakan tempat untuk mengkontruksi identitas masyarakat di sisi lain menjadi non mainstream tapi disisi lain bisa mengikuti budaya mainstream (Thornton, 1995). Gaya hidup perlawanan komunitas sepeda kebo dapat disebut sebagai subkultur, dimana disisi lain mengikuti budaya 
mainstream yaitu budaya modern yang dibawa arus globalisasi, namun juga bisa menjadi individu non mainstream yang digunakan untuk resistensi terhadap budaya modern yang sudah mengkikis budaya lokal. Gaya hidup komunitas sepeda kebo di Surabaya merupakan bentuk budaya tandingan (counter culture) terhadap budaya yang dibawa arus globalisasi yang posisinya sudah menjadi budaya dominan (mainstream) di Indonesia khususnya di Surabaya.

\section{Simpulan}

Pada komunitas sepeda kebo di Surabaya ditemukan bahwa makna komunitas sepeda kebo bagi anggotanya merupakan simbol kerukunan, persaudaraan, kekeluargaan, melestarikan budaya, dan guyub sesama onthelis. Komunitas sepeda kebo adalah wadah onthelis untuk menjalin kerukunan, persaudaraan, kekeluargaan dengan sesama pecinta sepeda kebo dan budaya tempo dulu untuk menciptakan suasana dan keadaan guyup antara onthelis. Keberadaan komunitas sepeda kebo dapat menjadikan onthelis awalnya tidak kenal bisa menjadi teman, dari teman menjadi saudara, dari saudara menjadi keluarga, dan akhirnya menjadi rukun dan guyup sesama onthelis. Komunitas sepeda kebo merupakan resistensi budaya dan budaya tandingan (counter culture) budaya lokal yaitu nilai-nilai ke-Indonesia-an (persaudaraan, kerukunanan, dan persatuan) terhadap nilai-nilai yang budaya yang dibawa era globalisasi yaitu individualis.

Makna menjadi anggota komunitas sepeda kebo adalah bentuk identitas sebagai individu yang memiliki kesadaran untuk melestarikan budaya, berjiwa sosial, sehat, dan kesederhanaan. Anggota komunitas sepeda kebo adalah individu yang memiliki motivasi untuk memiliki dan menggunakan budaya tempo dulu, memiliki rasa kebersamaan dan tolong menolong sesama onthelis serta masyarakat di luar komunitas sepeda kebo, sehat jasmani karena olah raga dengan menggunakan sepeda kebo, dan tidak menyombongkan diri serta saling menghargai antara onthelis guna menjalin kerukunan, persaudaraan, kekeluargaan, melestarikan 
budaya, dan guyub sesama onthelis. Identitas yang dikontruksi dalam komunitas sepeda kebo merupakan resistensi budaya dan budaya tandingan (counter culture) budaya lokal yaitu kepribadian ke-Indonesiaan (cita terhadap budaya lokal dan sejarah bangsa, tolong menolong, dan kebersamaan) terhadap identitas yang dibawa budaya di era globalisasi yaitu individualis, hidonis, dan kapitalis.

Dalam komunitas sepeda kebo terdapat ideologi persatuan dan kesatuan dan ideologi nasionalisme, dimana ideologi nasionalisme ditemukan pada motivasi anggota komunitas sepeda kebo memiliki dan menggunakan sepeda kebo dan budaya tempo dulu untuk menjaga eksisitensi dan keberadaan (melestarikan) budaya tempo dulu Indonesia. Ideologi persatuan dan kesatuan didapatkan dari motivasi anggota komunitas sepeda kebo untuk menggunakan komunitas sepeda kebo sebagai wadah untuk menjalin kerukunan, persaudaraan, kekeluargaan, melestarikan budaya, dan guyub sesama onthelis. Pembentukan ideologi nasionalisme dan ideologi persatuan dan kesatuan merupakan bentuk resistensi budaya dan budaya tandingan (counter culture) budaya lokal yaitu ideologi ke-Indonesia-an (ideologi nasionalisme dan ideologi persatuan dan kesatuan) terhadap ideologi yang dibawa budaya yang dibawa era globalisasi yaitu individualisme dan kapitalisme.

Komunitas sepeda kebo di Surabaya terbagi dua bagian pertama, mayoritas anggota komunitas sepeda kebo memiliki gaya hidup melawan atau memberikan solusi terhadap budaya mainstream atau dominan diwujudkan pada motivasi untuk memiliki sepeda kebo dan budaya tempo dulu serta baru digunakan pada acara komunitas sepeda kebo sedangkan dalam kehidupan sehari-harinya mengikuti gaya hidup mainstream atau dominan. Kedua, minoritas onthelis seperti onthelis yang melakukan Keliling Nusantara dan anggota komunitas sepeda kebo yang memiliki gaya hidup melawan atau memberikan solusi terhadap budaya mainstream atau dominan secara total yang diwujudkan dengan menggunakan sepeda kebo dan budaya tempo dulu dalam kehidupanya sehari-hari. 
Fenomena budaya komunitas sepeda kebo di Surabaya merupakan wujud subkultur era globalisasi sebagai bentuk gaya hidup dalam pembentukkan identitas hibrida yaitu tidak adanya identitas asli di sisi lain menjadi individu non mainstream tapi disisi lain bisa mengikuti budaya mainstream. Gaya hidup komunitas sepeda kebo merupakan resistensi terhadap budaya modern yang sudah mengkikis budaya lokal. Komunitas sepeda kebo di Surabaya merupakan bentuk budaya tandingan (counter culture) terhadap budaya yang dibawa arus globalisasi yang posisinya sudah menjadi budaya dominan (mainstream).

\section{Daftar Pustaka}

Barker, C. 2003.Cultural Studies: Theory and Practice.London: SAGE Publications

2011. Cultural Studies:Teori dan Praktik.Bantul:KREASI WACANA

Bungin, M. B. 2008.Penelitian Kualitatif, Komunikasi, Ekonomi, Kebijakan Publik, dan Ilmu Sosial Lainya.Jakarta: Kencana.

Furcah, A. 1992. Pengantar Metode Penelitian Kualitatif : Suatu Pendekatan Fenomenologi Terhadap Ilmu-Ilmu Sosial. Surabaya: Usaha Nasional.

Hall, S. 1992. The Question of Cultural Identity, dalam S. Hall, D. Held, dan T. McGrew (eds) Modernity and Its Futures. Cambridge: Polity Press.

Hartley, D. 1976. Subcultur The Meaning Of Style. London: Routledge.

Hebdige, D. 1999. Subculture: The Meaning of Style. Routledge, London and New York. New York: Methuen \& Co. Ltd.

Kuswarno, E. 2009. Fenomenologi: Metodologi Penelitian Komunikasi, Konsep, Pedoman, dan Contoh Penelitian. Bandung: Widya Padjadjaran.

Lina, S.A. 2009. Romantisme Sepeda onthel, (online), (www.indosiar.com/ragam/romantisme-sepeda-onthel.html, diakses 25 Juli 2014: 14.30).

Patton, M. Q. 1990. Qualitative evaluation and research methods (2nd ed.). Newbury Park, CA: Sage Publications.

Piliang, Y. A. 2003. Hipersemiotika, Tafsir Cultural Studies Atas Matinya Makna. Yogyakarta: Jalasutra.

Thornton, S. 1995. Club Cultures: Music, Media, and Subcultural Capital. Cambridge: Polity Press.

Soedarsono. 2002. Seni Pertunjukan Indonesia Di Era Globalisasi.Yogyakarta: Gajah Mada Universty Press.

www.kosti.or.id/pengprov/pengurus kosti propinsi, diakses 27 Mei 2014: 13.00 . 
LAKON VOL.4 NO 1/2015

http://onthelclassic.wordpress.com/komunitas/ diakses 27 Mei 2014:

15.00 . 